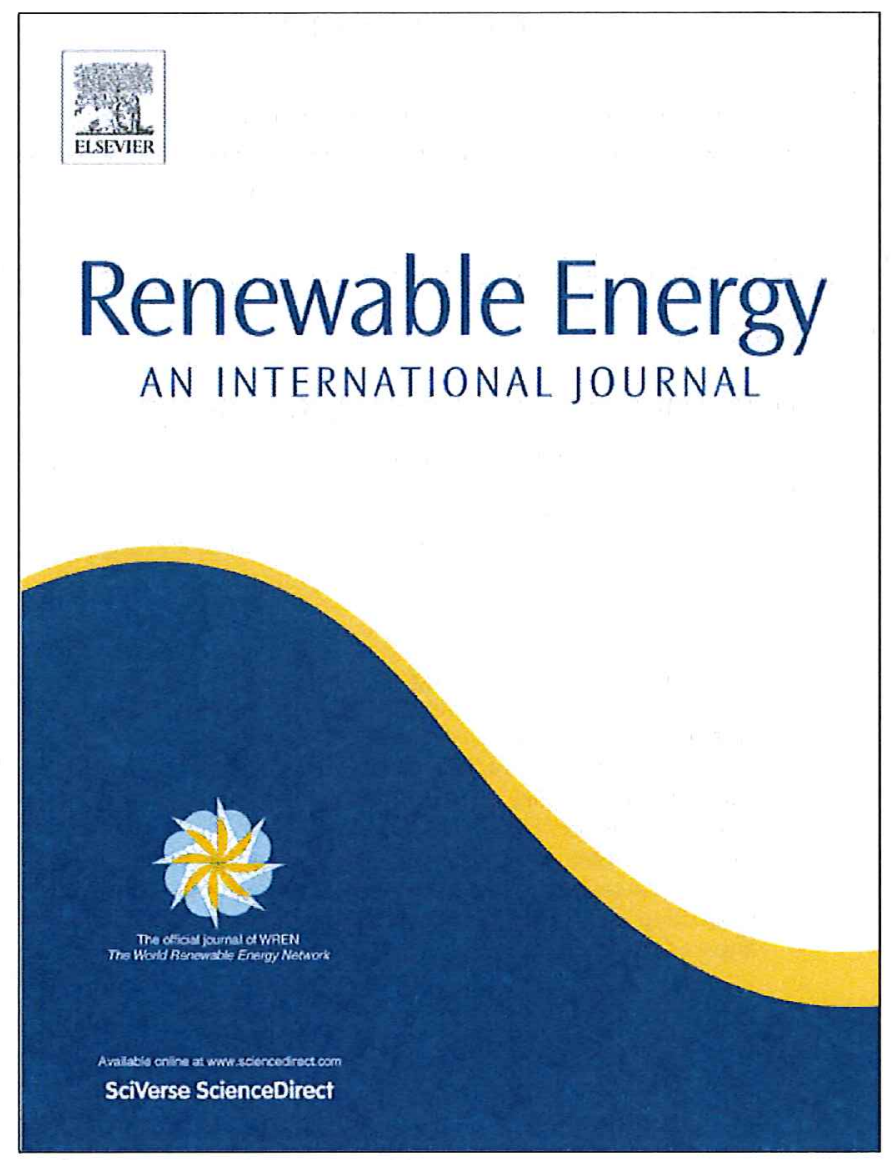

(This is a sample cover image for this issue. The actual cover is not yet available at this time.)

This article appeared in a journal published by Elsevier. The attached copy is furnished to the author for internal non-commercial research and education use, including for instruction at the authors institution and sharing with colleagues.

Other uses, including reproduction and distribution, or selling or licensing copies, or posting to personal, institutional or third party websites are prohibited.

In most cases authors are permitted to post their version of the article (e.g. in Word or Tex form) to their personal website or institutional repository. Authors requiring further information regarding Elsevier's archiving and manuscript policies are encouraged to visit:

http://www.elsevier.com/copyright 
Technical note

\title{
Progression of lipid profile and cell structure in a research-scale production pathway for algal biocrude
}

\author{
C.M. Beal $^{\mathrm{a}, \mathrm{b}, *}$, R.E. Hebner ${ }^{\mathrm{a}, \mathrm{b}}$, D. Romanovicz ${ }^{\mathrm{c}}$, C.C. Mayer ${ }^{\mathrm{a}}$, R. Connelly ${ }^{\mathrm{b}}$ \\ ${ }^{a}$ Department of Mechanical Engineering, University of Texas at Austin, Austin, TX 78712, USA \\ ${ }^{\mathrm{b}}$ The Center for Electromechanics, University of Texas at Austin, Austin, TX 78712, USA \\ 'Institute for Cellular and Molecular Biology, University of Texas at Austin, Austin, TX 78712, USA
}

\section{A R T I C L E I N F O}

\section{Article history:}

Received 21 May 2011

Accepted 16 June 2012

Available online $\mathrm{xxx}$

\section{Keywords:}

Biofuel

Algae

Biocrude

Biodiesel

Lipid

Production pathway

\begin{abstract}
A B S T R A C T
Although there has been a large research effort associated with individual parts of various algal biofuel production pathways, few studies have tracked changes in product composition throughout an integrated biofuel production process. This study uses microscopy and chromatography to analyze the progression of lipid profile and cell structure of algal cells throughout a research-scale production pathway for biocrude. For the specific processing methods used in this pathway, it is shown that TAG content decreased, while DAG and FFA content increased during processing. The changes in the lipid content corresponded to cell degradation that was observed by SEM and TEM throughout processing. These results demonstrate the dynamic nature of lipid composition in an algal culture used for biofuel production and emphasize the need to monitor changes in lipid profile, as those changes can directly impact biofuel productivity.
\end{abstract}

(C) 2012 Elsevier Ltd. All rights reserved.

\section{Introduction}

Algae have emerged as a promising biofuel feedstock that can be used to produce several different fuel products, including ethanol, renewable diesel, hydrogen, methane, and biomass for electricity [1-3]. This study characterizes the progression of the algal lipid profile and cell structure throughout an integrated research-scale production pathway. The production pathway has been described previously $[1,4,5]$ and consists of outdoor algal growth, harvesting, cell lysing, and lipid separations.

There is a general lack of methodology for tracking the changes in product composition throughout algal biocrude production. The lipid content is almost exclusively reported during growth [6-10]. A few studies have considered the effect of lipid content or lipid type on conversion processes (thermochemical conversion or transesterification) [11-15]. The lipid profile of microalgae used for aquaculture feed, and changes during storage, is often measured $[16,17]$. However, little information is available regarding changes in the lipid content throughout large-scale biofuel production, and the changes might be significant $[8,18-20]$. Furthermore, lipids are often reported in total $[6,12,15,21]$, while individual lipid species,

* Corresponding author. The Center for Electromechanics, 1 University Station C2200, Austin, TX 78712, USA.

E-mail addresses: colinmbeal@gmail.com, cbeal@mail.utexas.edu (C.M. Beal). such as mono-, di-, and triglycerides (MAG, DAG, and TAG), free fatty acids (FFA), and long chain hydrocarbons (LCH), are rarely tracked throughout production. In this study, thin layer chromatography (TLC), scanning electron microscopy (SEM), and transmission electron microscopy (TEM) are used to characterize the progression of lipid profile and cell structure throughout the biocrude production pathway.

\section{Materials and methods}

\subsection{Production pathway}

The production pathway analyzed in this study is shown in Fig. 1. A marine Chlorella species (KAS 603, provided by Kuehnle AgroSystems, Inc.) was used for three batches. Three growth volumes were used, as shown in Fig. 2. A cyanobacterial contaminant (believed to be Pseudoanabaena sp. [22]) was present in Batch 1 and Batch 2, and the relative amount of lipids in the cyanobateria, is not known. Although the contamination is undesirable, it is expected to be representative of future large-scale algal biomass production for biofuels.

Chlorella were cultivated with modified F/2 medium, including: Instant Ocean salt $(15 \mathrm{~g} / \mathrm{L})$, urea $(882 \mu \mathrm{M})$, sodium phosphate monobasic hydrate $(36.2 \mu \mathrm{M})$, ferric chloride hexahydrate $(11.7 \mu \mathrm{M})$, EDTA dehydrate $(11.7 \mu \mathrm{M})$, manganese (II) chloride 


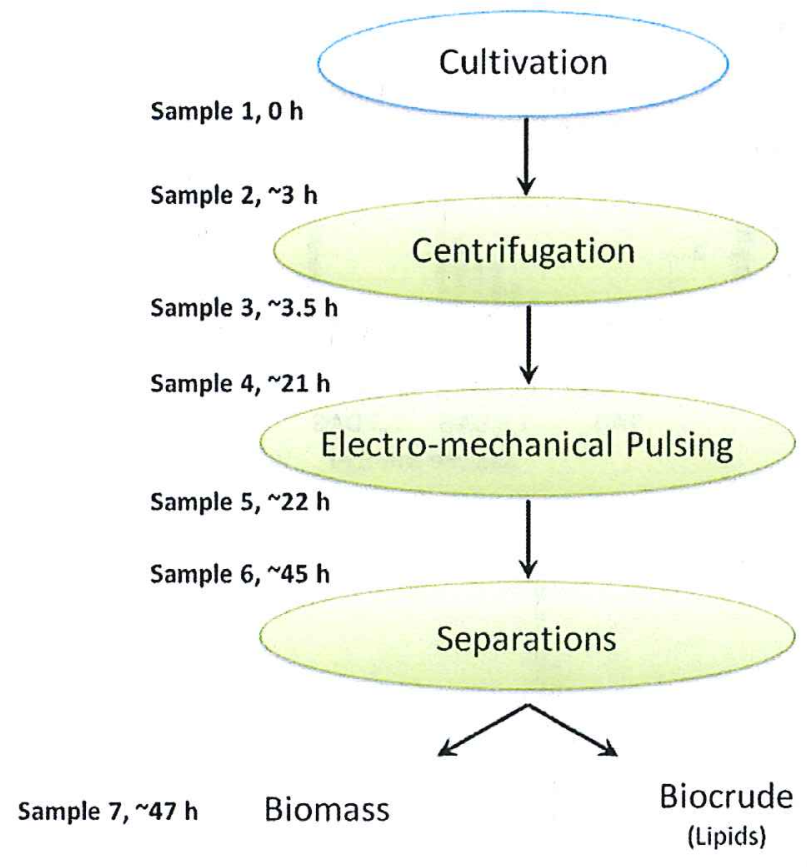

Refining: Not Conducted

Fig. 1. The production pathway includes cultivation, harvesting via centrifugation, electromechanical pulsing, and lipid separations via solvent extraction.

tetrahydrate $(0.91 \mu \mathrm{M})$, copper sulfate pentahydrate (39.3 nM), zinc sulfate heptahydrate (76.5 nM), cobalt (II) chloride hexahydrate (42 nM), sodium molybdate dihydrate (26 nM), vitamin B12 (369 $\mathrm{pM})$, vitamin $\mathrm{H}$ (2.05 nM), and vitamin B1 (296 nM) (cf. utex.org). The greenhouse tank was also continuously supplied with a $\mathrm{CO}_{2} /$ air mixture to maintain a $\mathrm{pH}$ of $\sim 7.5-8$. Indoor cultures (in both airlift bioreactors) were maintained at $\sim 24^{\circ} \mathrm{C}$, were supplied with artificial illumination with a $12 \mathrm{~h}$ on/off cycle, and a continuous stream of $1.1 \% \mathrm{CO}_{2}$ in air. The $\mathrm{CO}_{2}$ /air mixture exhausted from the bioreactor was $\sim 0.81 \% \mathrm{CO}_{2}$, on average. For Batch $1,40 \mathrm{~L}$ was obtained from the greenhouse tank, with an algal concentration of $0.033 \mathrm{~g} / \mathrm{L}$. In Batch 2, $20 \mathrm{~L}$ from the $100 \mathrm{~L}$ indoor bioreactor was combined

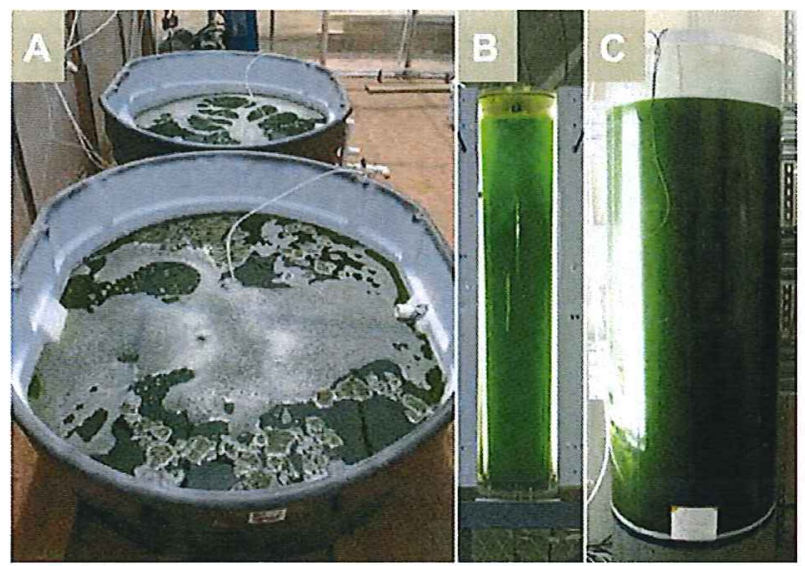

Fig. 2. A) Greenhouse tanks B) $100 \mathrm{~L}$ indoor, artificailly lit photobioreactor C) $300 \mathrm{~L}$ indoor artificially lit photobioreactor. with $20 \mathrm{~L}$ from the greenhouse tank, yielding an algal concentration of $0.46 \mathrm{~g} / \mathrm{L}$. For Batch 3, $80 \mathrm{~L}$ were harvested from the $300 \mathrm{~L}$ indoor bioreactor with an algal concentration of $0.41 \mathrm{~g} / \mathrm{L}$.

A centrifuge (Westfalia Separator, model SA 1-01-175) was used to concentrate the algae for this study. Centrifugation yielded algal concentrations of $1.95 \mathrm{~g} / \mathrm{L}, 41.87 \mathrm{~g} / \mathrm{L}$, and $15.83 \mathrm{~g} / \mathrm{L}$, which represent concentration factors of $57 \times, 91 \times$, and $39 \times$, respectively. After concentration, the algae were left in a dark container at room temperature $\left(\sim 24^{\circ} \mathrm{C}\right)$ overnight (for about $18 \mathrm{~h}$ ).

The concentrated algae were then exposed to electromechanical pulsing in a process designed to lyse the cells [4]. After lysing, the algae were again left in a dark container at room temperature $\left(\sim 24^{\circ} \mathrm{C}\right.$ ) overnight (for about $20 \mathrm{~h}$ ).

A custom extraction process was used to separate lipids from the other biomass. The algal biomass was suspended in methanol at $80^{\circ} \mathrm{C}$ for $1 \mathrm{~h}$, the methanol fraction was removed, the biomass was re-suspended in hexane, and again incubated at $80^{\circ} \mathrm{C}$ for $1 \mathrm{~h}$. The recovered lipids were stored at $4{ }^{\circ} \mathrm{C}$ until TLC analysis. Lipid composition of the post-extraction biomass was only evaluated for Batch 3.

\subsection{Sample collection}

Table 1 lists the samples that were collected and the approximate times that each sample was collected. For Batch 3, the dry weight and TLC analyses were conducted in triplicate. After collection, the samples were refrigerated until they were processed for TLC analysis ( $0-2 \mathrm{~h}$ after collection). For electron microscopy, only samples from Batch 2 were analyzed and all samples were fixed immediately upon collection.

\subsection{Dry weight}

The algal concentration was determined for each sample listed in Table 1. These samples were centrifuged and the pellet was washed three times to remove salts. Then, the samples were heated at $70{ }^{\circ} \mathrm{C}$ until constant weight was obtained.

\subsection{Thin layer chromatography}

For lipid composition analyses, all samples were centrifuged and the pellet and supernatant were analyzed separately. The supernatant fractions were treated sequentially with methanol and chloroform. Following intense vortexing and separation of the liquid phases, the organic phase was collected. This process was repeated with chloroform two additional times and the organic phases containing released lipids were pooled. The algal biomass pellets were re-suspended in methanol and heated to $65{ }^{\circ} \mathrm{C}$ for $30 \mathrm{~min}$. Following centrifugation, the methanol fraction was collected. The remaining pellet was re-suspended in chloroform:methanol (4:1), vortexed, and incubated at $50{ }^{\circ} \mathrm{C}$ for an additional $30 \mathrm{~min}$. The recovered organic fraction was pooled with

Table 1

Samples collected.

\begin{tabular}{lllllll}
\hline Description & $\# 1$ & Time, Vol. & $\# 2$ & Time, Vol. & \#3 & Time, Vol. \\
\hline Pond & $1-1$ & $0 \mathrm{~h}, 1 \mathrm{~L}$ & $2-1$ & $0 \mathrm{~h}, 1 \mathrm{~L}$ & $3-1$ & $0 \mathrm{~h}, 100 \mathrm{~mL}$ \\
Pre-centrifuge & $1-2$ & $3 \mathrm{~h}, 1 \mathrm{~L}$ & $2-2$ & $6 \mathrm{~h}, 1 \mathrm{~L}$ & $3-2$ & $3 \mathrm{~h}, 100 \mathrm{~mL}$ \\
Post-centrifuge & $1-3$ & $3.5 \mathrm{~h}, 10 \mathrm{~mL}$ & $2-3$ & $6.5 \mathrm{~h}, 10 \mathrm{~mL}$ & $3-3$ & $3.5 \mathrm{~h}, 10 \mathrm{~mL}$ \\
Pre-lysing & $1-4$ & $21 \mathrm{~h}, 10 \mathrm{~mL}$ & $2-4$ & $24 \mathrm{~h}, 10 \mathrm{~mL}$ & $3-4$ & $21 \mathrm{~h}, 10 \mathrm{~mL}$ \\
Post-lysing & $1-5$ & $22 \mathrm{~h}, 10 \mathrm{~mL}$ & $2-5$ & $25 \mathrm{~h}, 10 \mathrm{~mL}$ & $3-5$ & $22 \mathrm{~h}, 10 \mathrm{~mL}$ \\
Pre-extraction & $1-6$ & $45 \mathrm{~h}, 10 \mathrm{~mL}$ & $2-6$ & $45 \mathrm{~h}, 10 \mathrm{~mL}$ & $3-6$ & $45 \mathrm{~h}, 10 \mathrm{~mL}$ \\
Post-extraction & & & $2-7^{\mathrm{a}}$ & $47 \mathrm{~h}, 0.5 \mathrm{~mL}$ & $3-7$ & $47 \mathrm{~h}, 10 \mathrm{~mL}$ \\
\hline
\end{tabular}

a Sample 2-7 was analyzed by SEM and TEM, but not TLC.

b Triplicate dry weight and TLC analyses were conducted on all samples in Batch 3. 
A

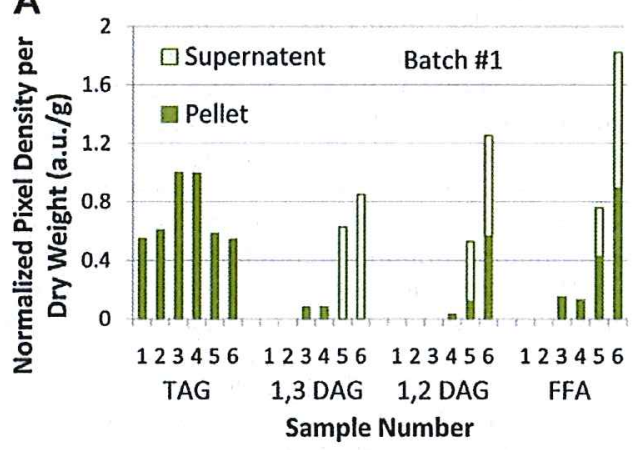

B

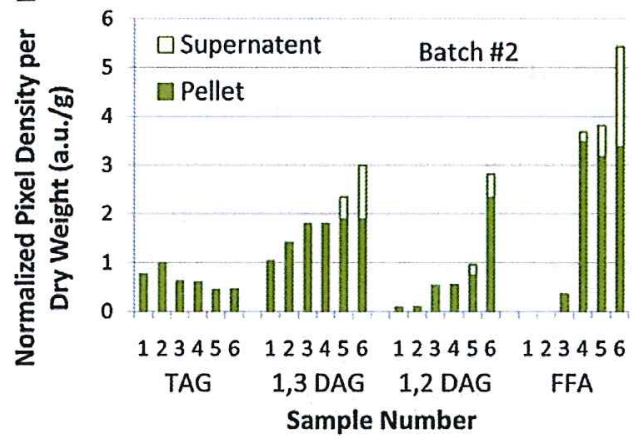

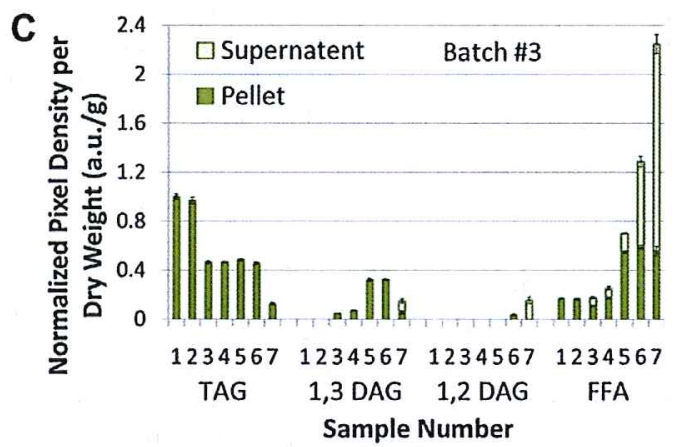

Fig. 3. The lipid content for each batch as indicated by pixel density (of the band associated with that lipid species) divided by algal dry weight of that sample. A) Batch 1 B) Batch 2 C) Batch 3 (error bars represent the standard deviation for triplicate samples).

the methanol fraction. Extracted lipids were re-suspended in $250 \mu \mathrm{L}$ of chloroform, and then stored at $4^{\circ} \mathrm{C}$ in the dark until TLC analysis.

For each sample, $5 \mu \mathrm{L}$ was spotted onto a $15-\mu \mathrm{m}$-particle size silica-gel-matrix plate along with a series of lipid standards. Lipids were developed via a 2-part solvent system: chloroform followed by hexane:diethyl ether:acetic acid (80:19:1), then resolved with iodine vapors. This TLC procedure is only selective for unsaturated lipids. Image J software was used to quantify the pixel density of each band from photographs of the completed TLC plates. The lipid standard (Sigma Aldrich, cat. \#1787) consisted of $1 \mu \mathrm{g} / \mu \mathrm{L}$ each of glyceryl trioleate (TAG), 1,3-Diolein (1,3 DAG), 1,2-dioleoyl-racglycerol (1,2 DAG), monoolein (MAG), and oleic acid (FFA). Lipid standard curves were obtained with linear $R^{2}$ values greater than 0.97 for all species on all of the plates. However, several of the processing samples' bands produced pixel intensities that were outside the range of the standard curves. As a result, some bands could not be used for quantification, so, the pixel density values are used in this study as relative indicators of the amount of each lipid species.

The pixel density measured for every lipid species in a sample was divided by the dry weight of that sample, yielding data that
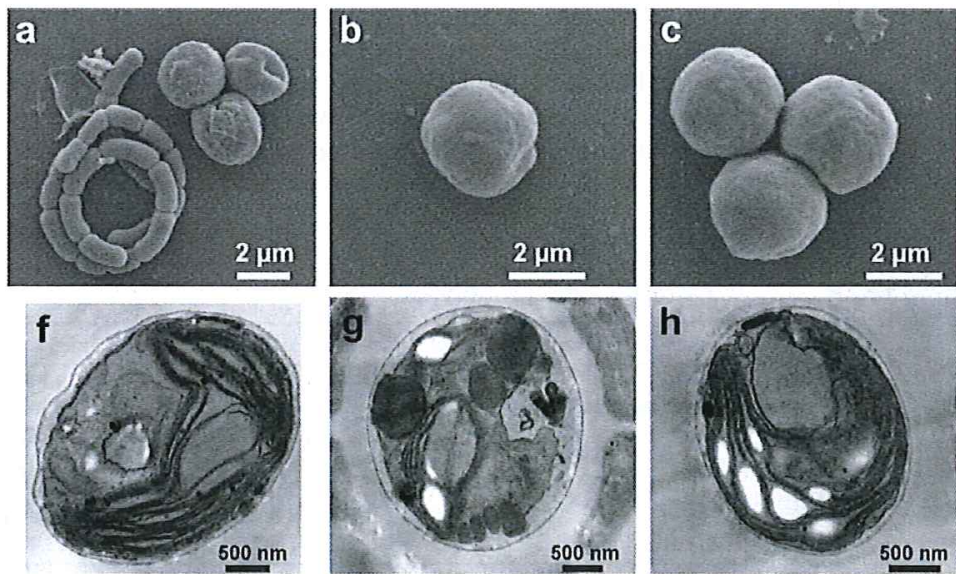
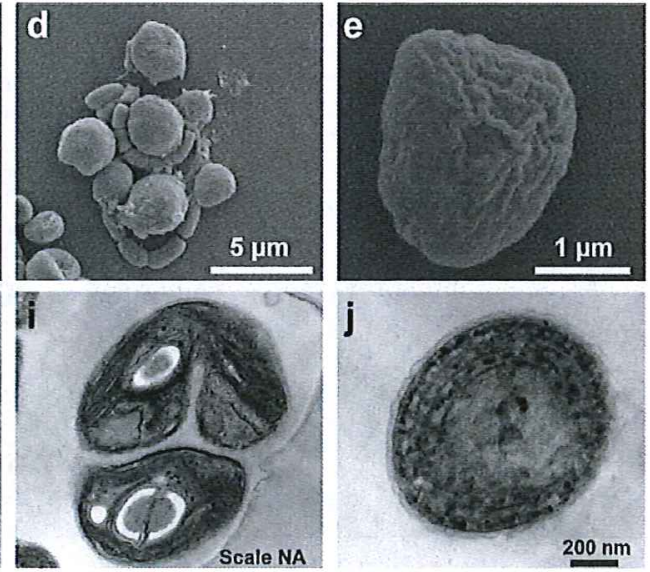

Fig. 4. a-e) SEM images for sample 2-1. f-j) TEM images for sample 2-1. 

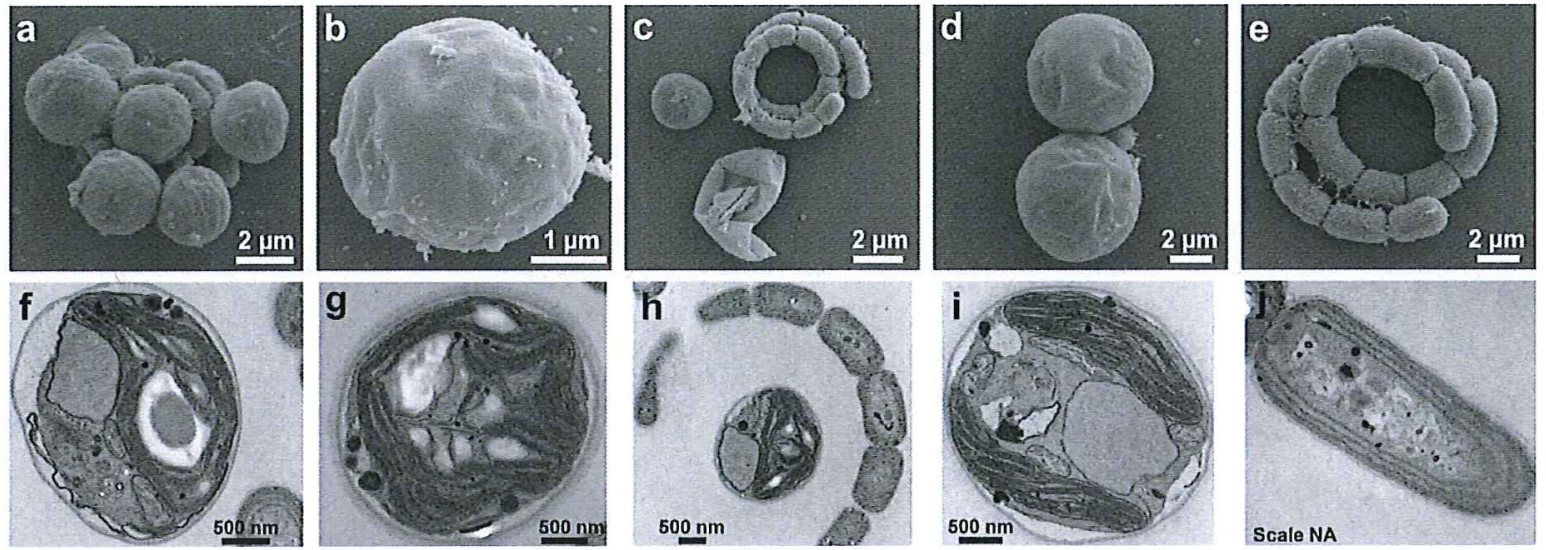

Fig. 5. a-e) SEM images for sample 2-2. f-j) TEM images for sample 2-2.

correlates to lipid content per gram of algae (in units of a.u./g). Finally, all of the 'pixel density per dry weight' values were normalized by the maximum value obtained for TAG within that batch. Appendix A contains the raw data for each sample.

\subsection{Electron microscopy}

Immediately after collection, $0.5 \mathrm{~mL}$ of each sample was added to $0.75 \mathrm{~mL}$ of fixative (2.5\% glutaraldehyde and $2 \%$ paraformaldehyde in
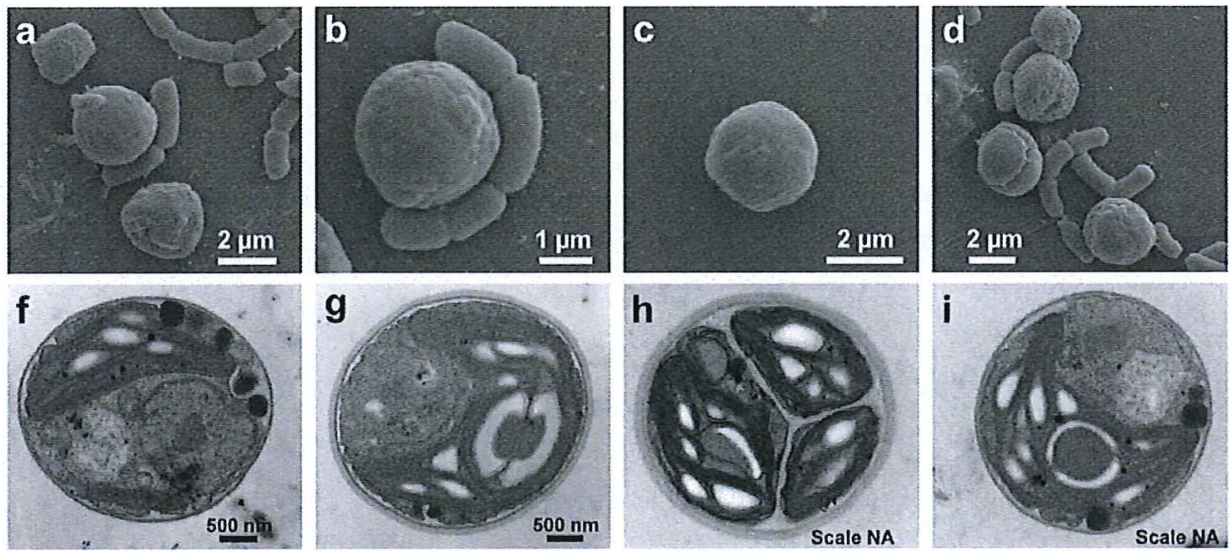

Fig. 6. a-e) SEM images for sample 2-3. f-j) TEM images for sample 2-3.
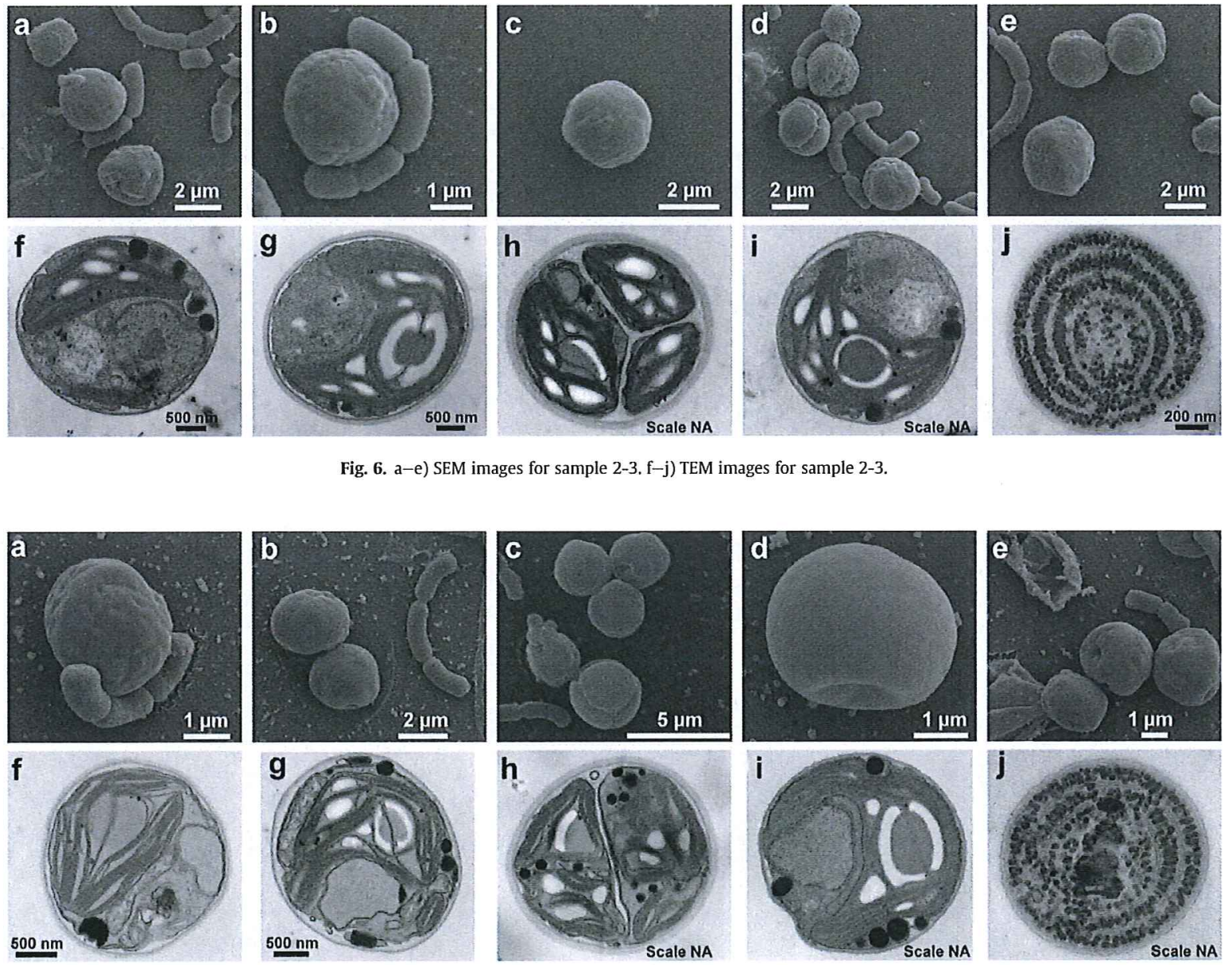

Fig. 7. a-e) SEM images for sample 2-4. f-j) TEM images for sample 2-4. 

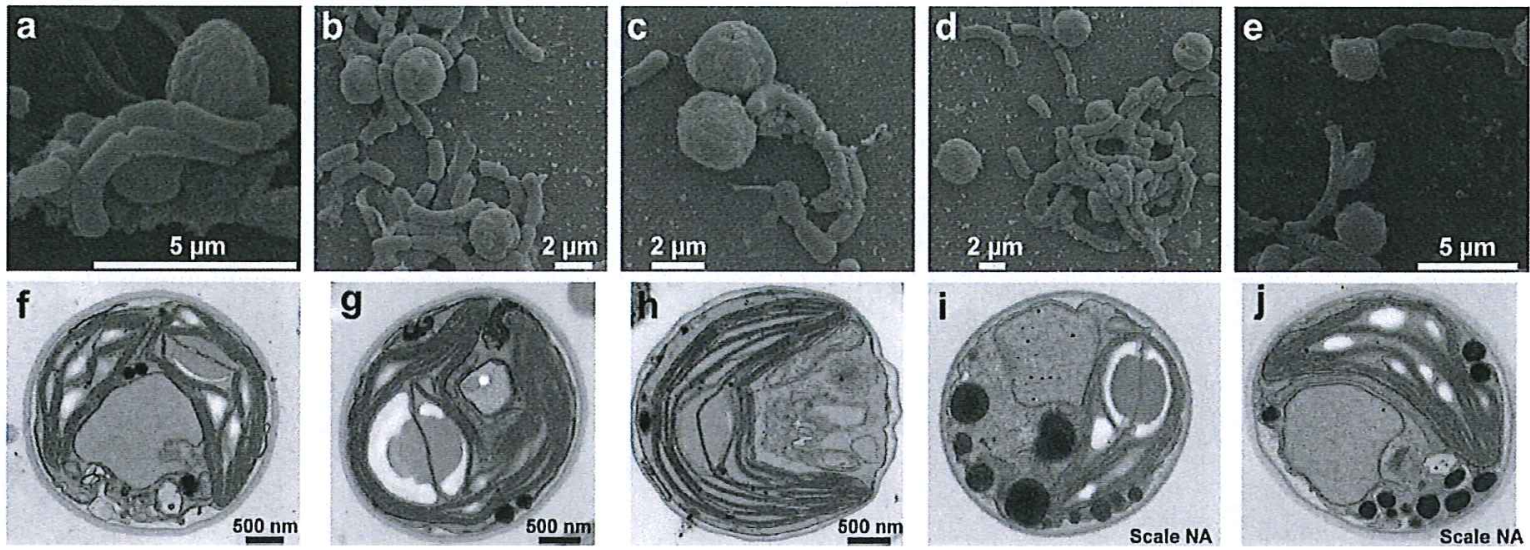

Fig. 8. a-e) SEM images for sample 2-5. f-j) TEM images for sample 2-5.

$0.1 \mathrm{M}$ cacodylate buffer $\mathrm{pH} 7.4$, similar to [23]), with $0.25 \mathrm{M}$ sucrose added as an osmotic substitute. After $\sim 18 \mathrm{~h}$, the samples were rinsed with $0.1 \mathrm{M}$ cacodylate buffer, decreasing the sucrose to zero in three steps, and then fixed with reduced osmium ( $2 \%$ osmium tetroxide and $2 \%$ potassium ferrocyanide in $0.1 \mathrm{M}$ cacodylate buffer
$7.4 \mathrm{pH}$ ). For scanning electron microscopy (SEM), the fixed samples were rinsed in $\mathrm{H}_{2} \mathrm{O}$, attached to glass with poly-L-lysine, dehydrated with ethanol $(50 \%-70 \%-95 \%-100 \%)$, and dried in a $\mathrm{CO}_{2}$ critical point dryer. The dried samples were sputter coated with $12 \mathrm{~nm}$ of iridium and imaged in a Zeiss Supra FE-SEM. For transmission
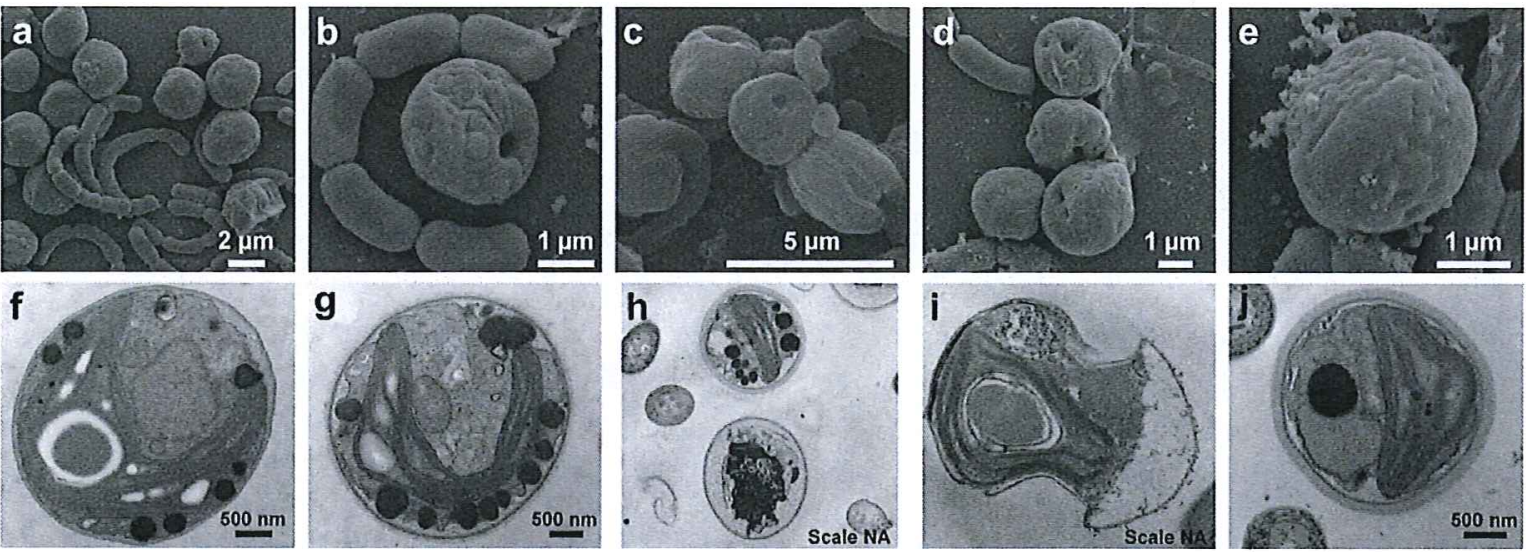

Fig. 9. a-e) SEM images for sample 2-6. f-j) TEM images for sample 2-6.
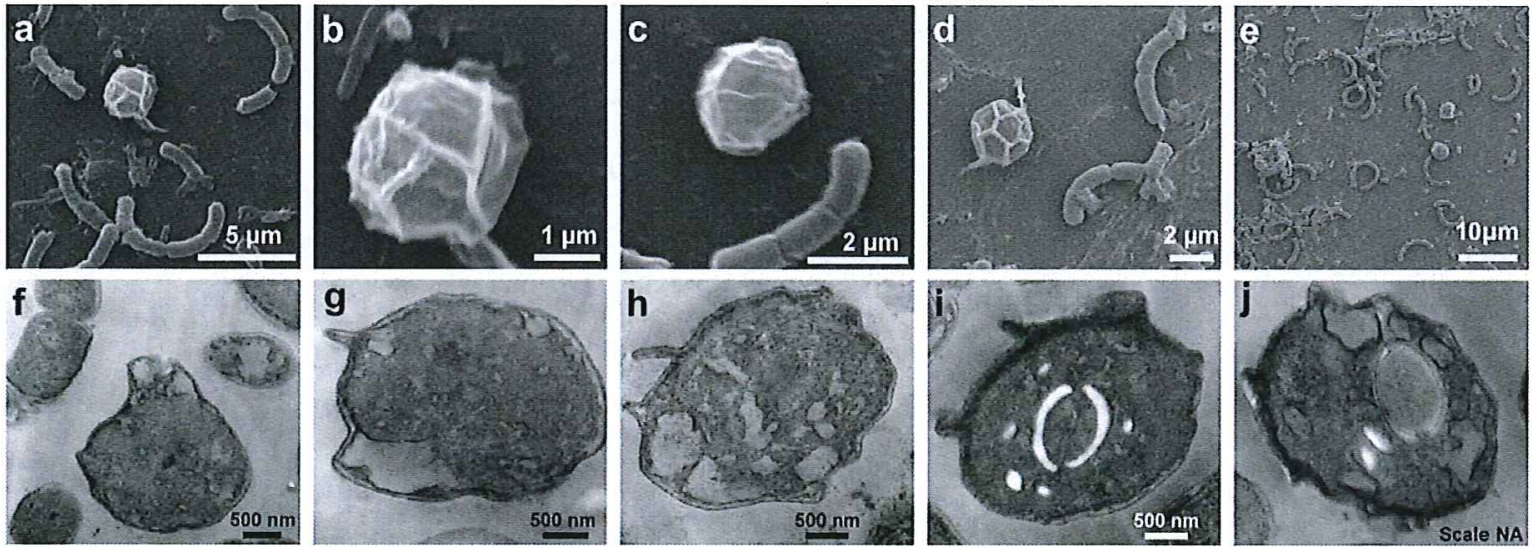

Fig. 10. a-e) SEM images for sample 2-7. f-j) TEM images for sample 2-7. 
electron microscopy (TEM), the cells after osmium fixation were encased in agar, infiltrated with epoxy resin (1:1 mixture of Spurr and EMBed 812, Electron Microscopy Sciences, Hatfield, PA), then sectioned and imaged at $80 \mathrm{kV}$ with an FEI Tecnai BioTwin TEM.

\section{Results and discussion}

\subsection{Lipid profile}

The trends observed for these batches, which are consistent with more than a dozen previous large-scale batches, include a decrease in TAG content and concurrent increases in 1,3 DAG, 1,2 DAG, and FFA content throughout processing, as shown in Fig. 3. Although these trends have been observed in all of the batches that have been processed, there is significant variability in the specific quantity of each lipid species in a given sample among batches (e.g., the TAG content in sample 5 among different batches). This variability is not uncommon for algal cultures. Triplicate samples were processed for Batch 3, and the standard deviation is shown with error bars in Fig. $3 c$.

The TAG content was a maximum in sample 1-2, 2-3, and 3-1 and then decreased by $51 \%, 47 \%$, and $54 \%$ in the pre-extraction samples (sample \#6) for batches 1,2 , and 3 , respectively. There was no TAG measured in the supernatant of the samples. For all three batches, the content of FFA and DAG $(1,3$ and 1,2) increased throughout processing (until extraction). In Batch 3, most of the TAG and DAG were recovered during extraction, however, the FFA content per dry weight of the post-extraction biomass (sample 3-7) was greater than the pre-extraction biomass. It is believed that the FFA detected in sample 3-7 were breakdown products (especially from phospholipids) that were produced as a result of the extraction process, but after the lipid phase (i.e., the biocrude) was removed.

The reduction in TAG content may be a metabolic result of lipid turnover as the algae were being exposed to severe stress conditions (darkness, change in temperature, high algal concentration, lack of $\mathrm{CO}_{2}$, change in oxygen concentration (not measured), and a change in nutrient availability (not measured)). Although algae can increase TAG content during cultivation under mild stress conditions [8], processing methods used in this study could have caused the algae to undergo catabolism, similar to the processes that occur at night $[20,24]$. It is also possible that the TAG was degraded into breakdown products, including DAG and FFA, during processing as a function of enzymatic lipase activity or physical degradation (e.g., resulting from electromechanical pulsing). Although chemical hydrolysis would also result in the conversion of TAG to DAG/FFA, this generally requires temperatures greater than $200{ }^{\circ} \mathrm{C}$ [25]. The increase in DAG and FFA shown in Fig. 3 is generally coincident with the decreases in TAG. However; in all cases, there is a greater increase in the DAG and FFA content during processing than there is a decrease in the TAG content, suggesting that other sources, such as phospholipids, are responsible for; or contribute to, the DAG and FFA content increase.

Previous studies have shown the breakdown of complex lipids of various organisms into DAG and/or FFA [26-32], especially under stress [29]. DAG and FFA are produced from TAG as precursors for phospholipid synthesis [28-30] and can also be produced from membrane phospholipids such as phosphotidylethanolamine (PE) and phosphotidylcholine (PC) $[26-28,31,32]$. The presence of lipids in the supernatant fraction occurs mainly in post-lysing samples, which supports the hypothesis that these lipid species are produced from phospholipid membranes. It is not clear exactly which biological, chemical, and physical processes were acting on the algae in this experiment.

\subsection{Cell structure}

Figs. 4-10 show SEM and TEM images obtained for Batch 2 . Most of the images focus on the algal cells, however cyanobacteria are specifically shown in Figs. $4 \mathrm{j}, 5 \mathrm{j}, 6 \mathrm{j}, 7 \mathrm{j}$. The cells in sample $2-4$ (pre-lysis) begin to appear "puckered" and in a few cases, the cells contain significant invaginations or holes. Post-lysis cells (sample 2-5) are damaged, non-spherical, and wrinkled. Although the external structure begins to deteriorate in samples $2-4$ and $2-5$, the internal structure and compartmentalization appear to be intact, at least for most of the cells in these samples. About $20 \mathrm{~h}$ after lysing the cells are significantly damaged internally and externally, and in many cases the cells developed holes. Finally, only a few algal cells appear in the SEM images obtained for the post-extraction biomass (sample 2-7), and these cells are severely damaged, as expected.

In addition to the drastic degradation between samples 2-6 and $2-7$, there were also significant structural changes between samples 2-3 and 2-4 and between sample 2-5 and 2-6. These intervals correspond to times when the algae were left in a dark container at high algal concentration ( $\sim 40 \mathrm{~g} / \mathrm{L}$ ) overnight following either centrifugation or electromechanical pulsing, respectively.

\section{Conclusions}

The results presented in this study are consistent with those observed during more than a dozen large-scale batches $(\sim 2000 \mathrm{~L}$ each) processed using a similar production pathway. Thus, it is believed that the trends observed, namely a decrease in TAG content and an increase in DAG/FFA content, are characteristic of the research-scale production pathway used here. Based on the chromatography and microscopy results, it is proposed that DAG and FFA are generated as breakdown products of TAG and phospholipids. The breakdown could occur physically (due to damage imposed by processing methods) or biochemically (e.g., via lipase activity). The thrust of this study is to demonstrate that changes in lipid profile and cell structure can occur and that these changes can affect the final biofuel yield. This work is not, however, a summary of a full understanding of the mechanisms responsible for the observed behavior. Nor are the results presented here necessarily representative of other production pathways.

The value of this study is to demonstrate that the algal lipid composition can change during biofuel processing and to provide a relatively simple method for tracking these changes throughout an integrated production pathway. It is important to monitor lipid content changes, especially during the production of petroleum fuel substitutes from algal biocrude (i.e., lipids). Not only does the amount of lipid impact the biofuel yield, but also the type of available lipids affects production methods as different lipids will require different downstream processing techniques.

\section{Acknowledgments}

We would like to acknowledge and thank the entire algal biofuel research group at the Center for Electromechanics. Specifically, we would like to acknowledge Mike Werst, Robert Pearsall, Steve Briggs, Bruce Morrison, and Patrice Palmer. We would also like to thank OpenAlgae LLC and the Webber Energy Group for partial funding.

\section{Appendix A. Data}

Table A1 lists the data obtained for each of the samples in batches 1, 2, and 3. The data presented for Batch 3 are averages across the triplicate samples analyzed and the standard deviation for these data are listed below. The samples are listed in Table 1 and shown in Fig. 1. 
Table A1

Algal concentration (DW/L, in grams per liter), the pixel density (in a.u., "Pix Dens") for each lipid species (TAG, 1,3 DAG, 1,2 DAG, and FFA) as measured by Image J, and the value for the normalized pixel density per dry weight (a.u., "Norm. Pix Dens/DW").

\begin{tabular}{|c|c|c|c|c|c|c|c|c|c|}
\hline Sample & $\begin{array}{l}\mathrm{DW} / \mathrm{L} \\
(\mathrm{g} / \mathrm{L})\end{array}$ & $\begin{array}{l}\text { TAG Pix } \\
\text { Dens }\end{array}$ & $\begin{array}{l}\text { TAG Norm. } \\
\text { Pix Dens/DW }\end{array}$ & $\begin{array}{l}\text { 1,3 DAG Pixel } \\
\text { Dens }\end{array}$ & $\begin{array}{l}\text { 1,3 DAG Norm. } \\
\text { Pix Dens/DW }\end{array}$ & $\begin{array}{l}\text { 1,2 DAG } \\
\text { Pix Dens }\end{array}$ & $\begin{array}{l}\text { 1,2 DAG Norm. } \\
\text { Pix Dens/DW }\end{array}$ & $\begin{array}{l}\text { FFA Pix } \\
\text { Dens }\end{array}$ & $\begin{array}{l}\text { FFA Norm. } \\
\text { Pix Dens/DW }\end{array}$ \\
\hline 1-1P & 0.03 & 394.43 & 0.55 & 0.00 & 0.00 & 0.00 & 0.00 & 0.00 & 0.00 \\
\hline $1-1 \mathrm{~S}$ & 0.03 & 0.00 & 0.00 & 0.00 & 0.00 & 0.00 & 0.00 & 0.00 & 0.00 \\
\hline $1-2 P$ & 0.03 & 439.83 & 0.61 & 0.00 & 0.00 & 0.00 & 0.00 & 0.00 & 0.00 \\
\hline $1-2 S$ & 0.03 & 0.00 & 0.00 & 0.00 & 0.00 & 0.00 & 0.00 & 0.00 & 0.00 \\
\hline $1-3 P$ & 1.95 & 418.14 & 1.00 & 33.90 & 0.08 & 0.00 & 0.00 & 63.08 & 0.15 \\
\hline $1-3 S$ & 1.95 & 0.00 & 0.00 & 0.00 & 0.00 & 0.00 & 0.00 & 0.00 & 0.00 \\
\hline $1-4 \mathrm{P}$ & 1.93 & 411.22 & 0.99 & 0.00 & 0.00 & 12.92 & 0.03 & 53.68 & 0.13 \\
\hline $1-4 S$ & 1.93 & 0.00 & 0.00 & 0.00 & 0.00 & 0.00 & 0.00 & 0.00 & 0.00 \\
\hline $1-5 P$ & 1.81 & 225.83 & 0.58 & 38.55 & 0.10 & 47.25 & 0.12 & 166.10 & 0.43 \\
\hline $1-5 S$ & 1.81 & 0.00 & 0.00 & 243.13 & 0.63 & 157.95 & 0.41 & 128.01 & 0.33 \\
\hline $1-6 P$ & 1.80 & 209.04 & 0.54 & 201.74 & 0.52 & 217.28 & 0.56 & 344.32 & 0.89 \\
\hline $1-65$ & 1.80 & 0.00 & 0.00 & 327.83 & 0.85 & 266.79 & 0.69 & 359.08 & 0.93 \\
\hline $2-1 P$ & 0.46 & 1091.38 & 0.77 & 1477.43 & 1.04 & 121.62 & 0.09 & 0.00 & 0.00 \\
\hline $2-1 S$ & 0.46 & 0.00 & 0.00 & 0.00 & 0.00 & 0.00 & 0.00 & 0.00 & 0.00 \\
\hline $2-2 P$ & 0.46 & 1405.55 & 1.00 & 1984.82 & 1.41 & 134.54 & 0.10 & 0.00 & 0.00 \\
\hline $2-2 S$ & 0.46 & 0.00 & 0.00 & 0.00 & 0.00 & 0.00 & 0.00 & 0.00 & 0.00 \\
\hline $2-3 P$ & 41.76 & 795.70 & 0.62 & 2303.79 & 1.80 & 677.42 & 0.53 & 467.23 & 0.36 \\
\hline $2-3 S$ & 41.76 & 0.00 & 0.00 & 0.00 & 0.00 & 0.00 & 0.00 & 0.00 & 0.00 \\
\hline $2-4 P$ & 40.44 & 745.48 & 0.60 & 2347.21 & 1.89 & 684.22 & 0.55 & 4323.21 & 3.48 \\
\hline $2-4 S$ & 40.44 & 0.00 & 0.00 & 0.00 & 0.00 & 0.00 & 0.00 & 246.10 & 0.20 \\
\hline $2-5 P$ & 39.94 & 548.87 & 0.45 & 2390.33 & 1.95 & 911.14 & 0.74 & 3884.40 & 3.17 \\
\hline $2-5 S$ & 39.94 & 0.00 & 0.00 & 556.34 & 0.45 & 267.17 & 0.22 & 791.26 & 0.65 \\
\hline $2-6 P$ & 37.49 & 531.46 & 0.46 & 4333.18 & 3.76 & 2687.66 & 2.33 & 3884.38 & 3.37 \\
\hline $2-6 S$ & 37.49 & 0.00 & 0.00 & 1267.65 & 1.10 & 550.08 & 0.48 & 2367.11 & 2.06 \\
\hline 3-1P & 0.41 & 5193.00 & $1.00^{\circ}$ & 0.00 & 0.00 & 0.00 & 0.00 & 886.00 & 0.17 \\
\hline $3-15$ & 0.41 & 0.00 & 0.00 & 0.00 & 0.00 & 0.00 & 0.00 & 0.00 & 0.00 \\
\hline $3-2 P$ & 0.41 & 5068.67 & 0.97 & 0.00 & 0.00 & 0.00 & 0.00 & 860.00 & 0.16 \\
\hline $3-2 S$ & 0.41 & 0.00 & 0.00 & 0.00 & 0.00 & 0.00 & 0.00 & 0.00 & 0.00 \\
\hline $3-3 P$ & 15.83 & 9430.33 & 0.47 & 892.33 & 0.04 & 0.00 & 0.00 & 2235.00 & 0.11 \\
\hline $3-3 S$ & 15.83 & 0.00 & 0.00 & 0.00 & 0.00 & 0.00 & 0.00 & 1338.33 & 0.07 \\
\hline $3-4 P$ & 14.19 & 8451.67 & 0.47 & 1284.67 & 0.07 & 0.00 & 0.00 & 3185.67 & 0.18 \\
\hline $3-4 S$ & 14.19 & 0.00 & 0.00 & 0.00 & 0.00 & 0.00 & 0.00 & 1428.33 & 0.08 \\
\hline $3-5 P$ & 11.81 & 7329.67 & 0.48 & 4848.67 & 0.32 & 0.00 & 0.00 & 8345.67 & 0.55 \\
\hline $3-5 S$ & 11.81 & 0.00 & 0.00 & 0.00 & 0.00 & 0.00 & 0.00 & 2256.00 & 0.15 \\
\hline $3-6 P$ & 11.53 & 6766.00 & 0.46 & 4778.67 & 0.32 & 530.33 & 0.04 & 8721.00 & 0.59 \\
\hline $3-6 S$ & 11.53 & 0.00 & 0.00 & 0.00 & 0.00 & 0.00 & 0.00 & $10,303.33$ & 0.70 \\
\hline 3-7P & 8.65 & 1376.33 & 0.12 & 621.33 & 0.06 & 0.00 & 0.00 & 6179.00 & 0.56 \\
\hline $3-7 S$ & 8.65 & 0.00 & 0.00 & 1010.00 & 0.09 & 1693.00 & 0.15 & $18,678.67$ & 1.69 \\
\hline \multicolumn{10}{|c|}{ Standard deviation } \\
\hline $3-1 P$ & 0.00 & 152.43 & 0.02 & 0.00 & 0.00 & 0.00 & 0.00 & 19.47 & 0.00 \\
\hline 3-1S & 0.00 & 0.00 & 0.00 & 0.00 & 0.00 & 0.00 & 0.00 & 0.00 & 0.00 \\
\hline $3-2 P$ & 0.00 & 120.65 & 0.03 & 0.00 & 0.00 & 0.00 & 0.00 & 38.97 & 0.01 \\
\hline $3-2 S$ & 0.00 & 0.00 & 0.00 & 0.00 & 0.00 & 0.00 & 0.00 & 0.00 & 0.00 \\
\hline 3-3P & 0.30 & 114.31 & 0.01 & 29.37 & 0.00 & 0.00 & 0.00 & 169.72 & 0.01 \\
\hline $3-3 S$ & 0.30 & 0.00 & 0.00 & 0.00 & 0.00 & 0.00 & 0.00 & 196.01 & 0.01 \\
\hline 3-4P & 0.22 & 224.56 & 0.01 & 43.55 & 0.00 & 0.00 & 0.00 & 113.56 & 0.01 \\
\hline $3-4 S$ & 0.22 & 0.00 & 0.00 & 0.00 & 0.00 & 0.00 & 0.00 & 278.29 & 0.02 \\
\hline 3-5P & 0.08 & 158.14 & 0.01 & 147.51 & 0.01 & 0.00 & 0.00 & 78.27 & 0.01 \\
\hline $3-5 S$ & 0.08 & 0.00 & 0.00 & 0.00 & 0.00 & 0.00 & 0.00 & 65.64 & 0.00 \\
\hline $3-6 P$ & 0.15 & 112.41 & 0.01 & 149.37 & 0.01 & 79.56 & 0.01 & 117.20 & 0.02 \\
\hline $3-6 S$ & 0.15 & 0.00 & 0.00 & 0.00 & 0.00 & 0.00 & 0.00 & 599.63 & 0.04 \\
\hline $3-7 P$ & 0.47 & 111.59 & 0.01 & 112.08 & 0.01 & 0.00 & 0.00 & 170.40 & 0.04 \\
\hline $3-7 S$ & 0.47 & 0.00 & 0.00 & 124.29 & 0.02 & 242.50 & 0.03 & 452.55 & 0.08 \\
\hline
\end{tabular}

\section{References}

[1] Beal CM, Smith CH, Webber ME, Ruoff RS, Hebner RE. A framework to report the production of renewable diesel from algae. BioEnergy Research 2011;4:36-60.

[2] Amin S. Review on biofuel oil and gas production processes from microalgae. Energy Conversion and Management 2009;50:1834-40.

[3] Demirbas A. Use of algae as biofuel sources. Energy Conversion and Management 2010;51:2738-49.

[4] Beal CM. Constraints on algal biofuel production. In: Mechanical engineering. Doctoral dissertation. Austin TX: University of Texas at Austin; 2011

[5] Beal CM, Hebner RE, Webber ME, Ruoff RS, Seibert AF. The energy return on investment for algal biocrude: results for a research production facility. BioEnergy Research 2011:1-22.

[6] Converti A, Casazza AA, Ortiz EY, Perego P, Del Borghi M. Effect of temperature and nitrogen concentration on the growth and lipid content of Namnochloropsis oculata and Chlorella vulgaris for biodiesel production. Chemical Engineering and Processing: Process Intensification 2009;48:1146-51.
[7] Gouveia L, Marques A, da Silva T, Reis A. Neochloris oleabundans UTEX \#1185: a suitable renewable lipid source for biofuel production. Journal of Industrial Microbiology and Biotechnology 2009;36:821-6.

[8] Hu Q Sommerfeld M, Jarvis E, Ghirardi M, Posewitz M, Seibert M, et al. Microalgal triacylglycerols as feedstocks for biofuel production: perspectives and advances. The Plant Journal 2008;54:621-39.

[9] Liang Y, Sarkany N, Cui Y. Biomass and lipid productivities of Chlorella vulgaris under autotrophic, heterotrophic and mixotrophic growth conditions. Biotechnology Letters 2009;31:1043-9.

[10] Pruvost J, Van Vooren G, Cogne G, Legrand J. Investigation of biomass and lipids production with Neochloris oleoabundans in photobioreactor. Bioresource Technology 2009;100:5988-95.

[11] Levine RB, Pinnarat T, Savage PE. Biodiesel production from wet algal biomass through in situ lipid hydrolysis and supercritical transesterification. Energy \& Fuels 2010;24:5235-43.

[12] Miao X, Wu Q. Biodiesel production from heterotrophic microalgal oil. Bioresource Technology 2006;97:841-6. 
[13] Umdu ES, Tuncer M, Seker E. Transesterification of Nannochloropsis oculata microalga's lipid to biodiesel on $\mathrm{Al} 2 \mathrm{O} 3$ supported $\mathrm{CaO}$ and $\mathrm{MgO}$ catalysts. Bioresource Technology 2009;100:2828-31.

[14] Yamaberi K, Takagi M, Yoshida T. Nitrogen depletion for intracellular triglyceride accumulation to enhance liquefaction yield of marine microalgal cells into a fuel oil. Journal of Marine Biotechnology 1998;6:44-8.

[15] Li X, Xu H, Wu Q. Large-scale biodiesel production from microalga Chlorella protothecoides through heterotrophic cultivation in bioreactors. Biotechnology and Bioengineering 2007;98:764-71.

[16] Gladue R, Maxey J. Microalgal feeds for aquaculture. Journal of Applied Phycology 1994;6:131-41.

[17] Molina Grima E, Sánchez PérezJA, García Camacho F, Acién Fernández FG, López Alonso D, Segura del Castillo CI. Preservation of the marine microalga, Isochrysis galbana: influence on the fatty acid profile. Aquaculture 1994:123:377-85.

[18] Sukenik A, Carmeli Y. Lipid synthesis and fatty acid composition in Nannochloropsis $s p$. (Eustigmatophyceae) grown in a light-dark cycle. Journal of Phycology 1990;26:463-9.

[19] Zhu CJ, Lee YK, Chao TM, Lim SH. Diurnal changes in gross chemical composition and fatty acid profiles of Isochrysis galbana TK1 in outdoor closed tubular photobioreactors. Journal of Marine Biotechnology 1997;5:153-7.

[20] Guschina IA, Harwood JL. Lipids and lipid metabolism in eukaryotic algae. Progress in Lipid Research 2006;45:160-86.

[21] Chiu S, Kao C, Tsai M, Ong S, Chen C, Lin C. Lipid accumulation and CO2 utilization of Nannochloropsis oculata in response to $\mathrm{CO} 2$ aeration. Bioresource Technology 2009;100:833-8.

[22] Nobles D. (2010) Pseudoanabaena sp. Identification at UTEX algae culture collection. In:Personal Communication, Beal C.M.
[23] Karnovsky MJ. A formaldehyde-gluteraldehyde fixative of high osmolarity for use in electron micrsocopy. Journal of Cell Biology 1965;27.

[24] Radakovits R, Jinkerson RE, Darzins A, Posewitz MC. Genetic engineering of algae for enhanced biofuel production. Eukaryotic Cell 2010;9:486-501.

[25] Levine R.B. (2010) Chemical hydrolysis in algae. In:Personal Communication Beal C.M.

[26] Sasaki GC, Capuzzo JM. Degradation of artemia lipids under storage. Comparative Biochemistry and Physiology Part B: Comparative Biochemistry 1984;78:525-31.

[27] Brown JH, Lynch DV, Thompson JE. Molecular species specificity of phospholipid breakdown in microsomal membranes of senescing carnation flowers. Plant Physiology 1987;85:679-83.

[28] Athenstaedt $K$, Daum $G$. The life cycle of neutral lipids: synthesis, storage and degradation. Cellular and Molecular Life Sciences 2006;63: 1355-69.

[29] Berge JP, Gouygou JP, Dubacq JP, Durand P. Reassessment of lipid composition of the diatom, Skeletonema costatum. Phytochemistry 1995;39:1017-21.

[30] Fakas S, Galiotou-Panayotou M, Papanikolaou S, Komaitis M, Aggelis G. Compositional shifts in lipid fractions during lipid turnover in Cumninghamella echinulata. Enzyme and Microbial Technology 2007;40:1321-7.

[31] Pernet F, Tremblay R. Effect of ultrasonication and grinding on the determination of lipid class content of microalgae harvested on filters. Lipids 2003;38: 1191-5.

[32] Shrestha P, Cohen D, Khalilov I, Khozin-Goldberg I, Cohen Z. Triacylglycero biosynthesis in microsomes and oil bodies of the oleaginous green alg Parietochloris incisa. In: Proceedings of 16th International Plant lipid Symposium; 2004. Budapest, Hungary. 
